Historic, Archive Document

Do not assume content reflects current scientific knowledge, policies, or practices. 

A280.390

M34 


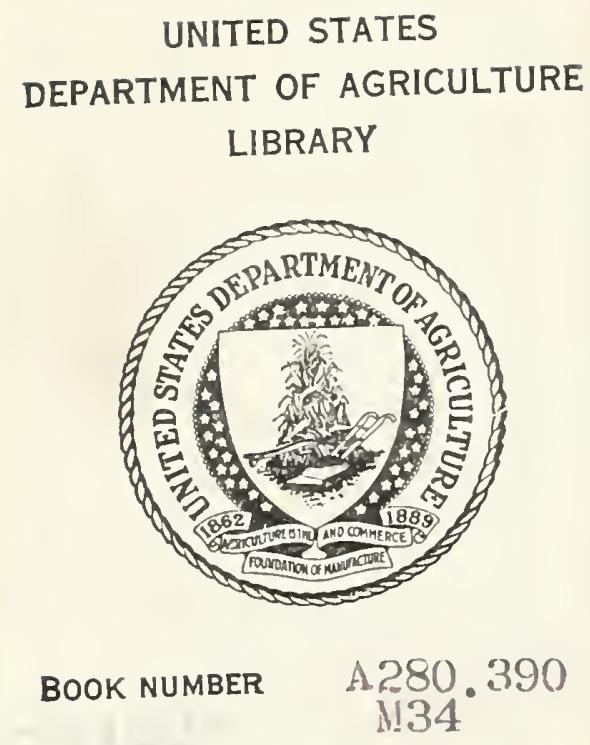




\section{PART I GENERAL}

In order to assure satisfactory delivery of processed fruits and vegetables, many state and federal agencies require inspection by the United States Department of Agriculture.

Purchases f processed fruits and regetables by these agencies normally require that the vendor assume the cost of inspection and certain related services such as checkloading or stamping of cases.

Since many of such purchases are limited to small lots and because awards are made on the basis of competitive bids, it is desirable that prospective vendors be provided a guide by which they may calculate the cost of inspection and stamping (or checkloading) services. ...

In view of the time incurred in sampling lots that require considerable travel, as well as the time required for added services such as stamping and checkloading, it is desirable to assess fees on the basis of the hourly rate (currently $\$ 4.00$ per hour) as provided for in Section 52.48, Part 52, Title 7, "Regulations Governing Inspection and certification."

The schedule of charges outlined herein is designed in such a manner as to provide a simplified procedure for computing the approximate cost of inspection of lots of processed products offered for delivery on contracts requiring the vendor to assume the cost of inspection. No additional charge is made for microanalyses or laboratory tests except canned tomato products in lots in excess of 300 cases in which numerous filth analyses may be required. Miscellaneous processed products such as spices, flavoring extracts and mayonnaise are also excluded from the proposed schedule.

In computing the cost of inspection when stamping or checkloading are required, vendors are cautioned to make the lots readily accessible for stamping or checkloading in order to avoid unnecessary delay or return trips which will increase the cost of the service. Generally speaking, it is to the contractor's advantage to have small lots stamped at the time of sampling. Checkloading will generally be cheaper on truckload or carload lots. Arrangements may be made with the sampler or inspector to handle the assignment in the most expeditious manner.

In applying the attached schedule, vendors will consider whichever of the following is applicable to the situation:

(1) IF CASES ARE TO BE STAMPED

(a) Determine the cost of inspection and stamping cases as outlined in paragraph I of the attached schedule. 
(b) To this fee add any travel costs or incidental expenses as outlined in paragraph III of the attached schedule.

(2) IF LOT IS TO BE CHECKLOADED

(a) Determine the cost of inspection as outlined in paragraph II of the attached schedule.

(b) Add the cost of checkloading. The time incurred for checkloading will depend to a great extent upon the available facilities and the vendor's ability to organize the loading with a minimum of delay.

(c) To the fee in (a) and (b) add any travel costs or incidental expenses as outlined in paragraph III of the attached schedule.

\section{PART II}

SCHEDULE FOR ESTIMATING COSTS OF INSPECTICN (INCLUDING STAMPING AND CHECKLOADING) WHEN CHARGES ARE BASED ON THE HOURLY RATE I]

"Lot" for the purpeses of this instruction means any number of containers of the same size and type which contain a pracessed product of the same type and style located in the same or adjacent warehouses and which are available for inspection at any one time.

I BASIC FEE FOR IN SPECTION AND STAMPING OF CASES

(1) Single lots of 100 cases or less - inspection. (including micranalyses) and stamping of cases ..

$$
\text { Each lot }-21 / 2 \text { hours } \$ 10.00
$$

(2) Two or more lots offered by same applicant at one time and one location -

$$
\text { Each lot of } 100 \text { cases or less }-2 \text { hours } \$ 8.00
$$

1/ This schedule is not applicable for processed products requiring detailed laboratory analyses such as flavoring extracts, spices, salad dressings, nor for lots of tomato products in excess of 300 cases which may require numerous microanalyses. Fees for these products may be ascertained by contacting the nearest Processed Products Standardization and Inspection field office. 
(3) Lots in excess of 100 cases, a charge at the rate of $1 / 2$ hour per 200 cases er fraction thereof is added to (I) or

(2) above to cover cost of stamping.

Each unit of 200 cases or fraction thereof $-1 / 2$ hour

(4) Travel costs and incidental expenses as outzined in paragraph III below.

II BASIC FEE FOR INSPECTTON AND CHECKLOADING

(1) Lots of 100 cases or less - inspection (including micranalyses)

$$
\text { Each lot - } 2 \text { hours } \$
$$

(2) Lots in excess of 100 cases but not over 600 cases inspection (including microanalyses)

Each lot - 3 hours

(3) Lots in excess of 600 cases - inspection (including microanalyses) -

Each Iot:

For the first 600 cases -3 hours $\$ 12.00$

For each unit of 200 cases, or fraction thereof, in excess of 600 cases $1 / 2$ hour

(4) Checkloading - $\$ 4.00$ per hour for time required to perform service.

(5) Travel costs and incidental expenses as outlined in paragraph III below.

\section{FEE FOR ADDITIONAL SERVICES AND EXPENSES}

The following additional charges, as may be applicable, shall be added to the fee in I or II above to arrive at the total cost of inspection. These charges shall be prorated whenever possible.

(1) Travel time at the rate of $1 / 2$ hour for each 20 miles, except - that no travel time will be charged for lots located in the - immediate vicinity of the field office (approximate radius of 5 miles).

(2) Mileage incurred at the rate of $7 \$$ per mile. 
(3) Per diem (if applicable) at the rate of $\$ 9.00$ per day. (Per diem is charged only when the sampler or inspector is required to be away from his official duty station for a period of more than a basic work day which is normally 8 A.M. to 6 P.M.)

(4) Miscellaneous expenses such as express for shipping samples and long distance telephone charges.

(5) Additional stamping charge of $\$ 4.00$ per hour whenever lots are not readily available for stamping at the time of sampling.

The following examples will serve to illustrate the method of computing the cost of inspection,

Example I (A lot of 190 cases located 4 miles from office and is to be stamped during sampling)

Fee for first 100 cases - $21 / 2$ hours

Fee for 90 cases $-1 / 2$ hour

Expenses ( 8 miles at .07 )

Total fee (including stamping)

Example 2 (Three lots of 90 cases, 130 cases and 350 cases offered at one time by same applicant)

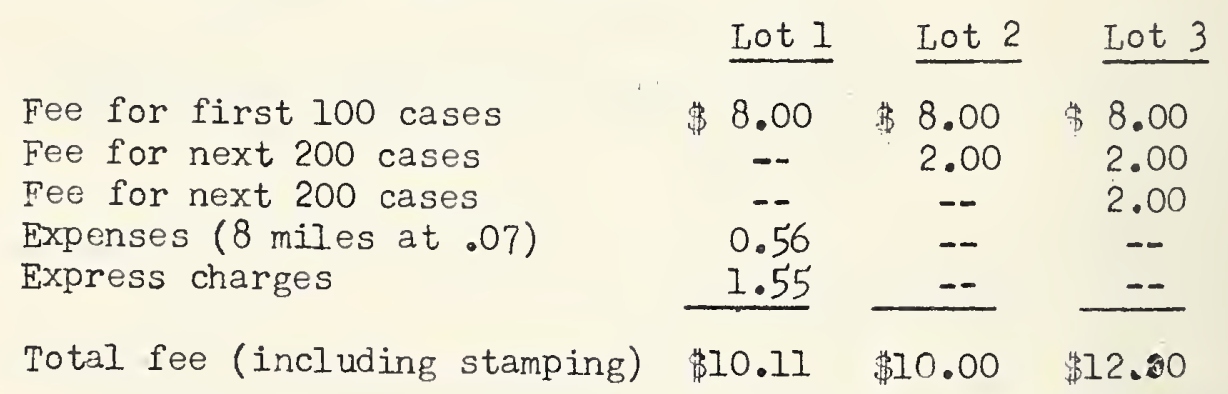

Example 3 (Lot of 1500 cases located 38 miles from field office. Vendor requests checkloading in lieu of stamping)

Fee for inspection:

(a) 3 hours for first 600 cases

(b) $1 / 2$ hour for each additional 200 cases ( 5 units at $1 / 2$ hour or $21 / 2$ hours)
time ( 76 miles) -2 hours Driving time ( 76 miles) -
Checkloading $-21 / 2$ hours

Mileage ( 76 miles at .07)

Total fee

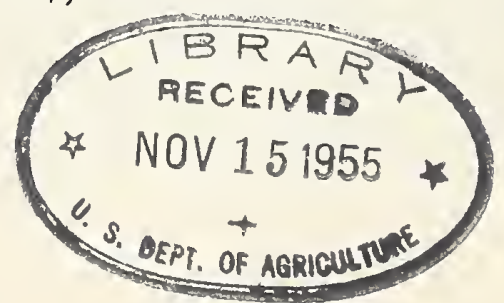



